\title{
LA REPRESENTACIÓN DE LAS RELACIONES INTERÉTNICAS EN EL DISCURSO DE ANTONIO VIEDMA (PATAGONIA MERIDIONAL, SIGLO XVIII)
}

\author{
SILVANA BUSCAGLIA*
}

\begin{abstract}
RESUMEN
El propósito del presente trabajo es abordar la construcción de las relaciones interétnicas en la colonia española de Floridablanca (San Julián, Provincia de Santa Cruz, siglo XVIII). La perspectiva que aquí proponemos integra el análisis de los discursos y las prácticas cotidianas a partir de la información suministrada por las fuentes históricas. En particular, se busca evaluar la representación de los tehuelches (aónikenk) en el discurso de Antonio Viedma en función de las implicancias del contacto y las prácticas indígenas para la puesta en práctica del ideal de sociedad que se buscó fomentar en la colonia.
\end{abstract}

PALABRAS CLAVES: Patagonia, siglo XVIII, vida cotidiana, discursos y prácticas sociales.

\section{THE REPRESENTATION OF INTERETHNIC RELATIONSHIPS IN ANTONIO VIEDMA 'S DISCOURSE (SOUTHERN PATAGONIA, $18^{\mathrm{TH}}$ CENTURY)}

\begin{abstract}
The aim of this paper is to analyze the interethnic relationship construction at the Spanish colony of Floridablanca (San Julián, Santa Cruz Province, $18^{\text {th }}$ century). Our analytic perspective integrates the discourses and daily practices from information provided by historical sources. In particular, we evaluate the representation of local tehuelches (aonikenk) in Antonio Viedma's discourse, considering the implications of contact and indigenous practices for the implementation of the ideal society which sought to promote in the colony.
\end{abstract}

KEY WORDS: Patagonia, $18^{\text {Th }}$ century, daily life, discourses and social practices. 


\section{INTRODUCCIÓN}

El presente trabajo tiene por objeto analizar el discurso de Antonio Viedma, Superintendente de la colonia de Floridablanca ${ }^{1}$ respecto a los tehuelches (aónikenk) y las relaciones interétnicas entabladas con los mismos durante el funcionamiento de dicha colonia. La misma fue establecida en la bahía de San Julián, Pcia. de Santa Cruz, Argentina y tuvo un corto período de funcionamiento entre 1780 y 1784 -Figura 1. El abordaje a la problemática señalada se organizará en torno a la discusión de un ideal de sociedad que se buscó fomentar en Floridablanca (Senatore [2003] 2007) y el modo en que las relaciones entabladas con los indígenas patagónicos así como sus prácticas cotidianas pudo haber afectado la puesta en práctica del mismo.

Los fundamentos teóricos que sustentan este abordaje se articulan en torno a conceptos que se desprenden de la Teoría Social (Giddens 1995; Bourdieu 1999), la Crítica Postcolonial (Fanon 1986; Spivak 1994; Castro Gómez y Mendieta 1998; Gosden 1999 y 2001; Bhabha 2002; Said 2006, Liebmann y Rivzi 2008; entre otros) y los Estudios de Subalternidad (Guha 1982; Mallon 1994; Prakash 1994; Spivak 1994, Rodríguez 1998 y 2001; entre otros). Dichas perspectivas han permitido el desarrollo de propuestas novedosas a la hora de discutir críticamente el colonialismo, los discursos generados por el mismo, así como la importancia de reconocer el rol activo de las sociedades nativas y las minorías para alterar las estructuras coloniales, aún en el marco de fuertes asimetrías de poder. De este modo, el contacto es entendido como un proceso bidireccional en el que no sólo los grupos locales experimentaron transformaciones sino también las sociedades colonizadoras (Di Paolo 2001; Stein 2005; Vives

1 Proyecto "Arquelogía e Historia en la Colonia española de Floridablanca, San Julián, siglo XVIII" bajo la dirección de la Dra. María Ximena Senatore. Los siguientes subsidios permitieron el financiamiento de las investigaciones: "Arqueología de la Modernidad" UBACyT F-453 (20082010); "Tiempos Modernos en Patagonia" de Fundación Antorchas (2004-2007), "Sociedad Moderna y Cultura Material" UBACyT F-076 (2004-2007), "Arqueología de la Sociedad Moderna en Antártida y Patagonia Meridional". Programa IM 40, Agencia Nacional de Promoción Científica y Tecnológica SECyT 2002-2005, todos ellos bajo la dirección de la Dra. Senatore.
Ferradiz Sánches 2006; Voss 2008; Buscaglia 2009, entre otros).

Los discursos (Foucault 1984; [1970] 1992) y las prácticas (Bourdieu 1999) constituyen los dos ejes analíticos para establecer el rol y la significación de aquellas prácticas más mundanas e "insignificantes" de los tehuelches en relación a las fomentadas por el proyecto colonizador. Si bien ambos constituyen dos dimensiones recursivas entre sí -los discursos son prácticas y las prácticas tienen una dimensión discursiva-, en este trabajo serán separados analíticamente a los efectos de simplificar su abordaje. Desde un punto de vista heurístico, nos interesa identificar e interpretar los significados de los espacios de desarticulación, entre los discursos generados desde el colonialismo y la dimensión cotidiana de las prácticas sociales -tanto indígenas como europeas. El análisis discursivo se centra en la identificación de enunciados marcados por contradicciones, distorsiones, ambigüedades y silencios. Es precisamente en estos lugares donde se hacen visibles y adquieren voz aquellos actores y prácticas que no dejaron evidencia escrita sobre sí mismos y que de alguna manera quedaron omitidos, negados y/o descalificados en el discurso colonial.

Las fuentes analizadas para la elaboración del presente trabajo son tanto éditas como inéditas. Entre las éditas se encuentra el Diario de Antonio Viedma y su Descripción de la costa sur meridional llamada vulgarmente patagónica... ([1783] 1972a y b respectivamente). En el primero, Viedma nos brinda un relato pormenorizado del funcionamiento de la colonia de Floridablanca durante los tres años que estuvo al frente de la misma, lo cual incluye el trato cotidiano con los tehuelches locales desde el arribo de expedición colonizadora. El segundo podría decirse que constituye una de las primeras y más pormenorizadas descripciones "etnográficas" de la vida y costumbres de los tehuelches meridionales, sentando un precedente para los posteriores relatos de viajeros y naturalistas.

Entre los documentos inéditos analizamos las cartas escritas por Antonio Viedma dirigidas a las autoridades virreinales, registros de contaduría elaborados por el contador de Floridablanca así como documentación generada desde los fuertes Nuestra Señora del Carmen y San José. Los documentos analizados se encuentran depositados en el Archivo General de la Nación [AGN], Buenos Aires 
Argentina, correspondiendo a la Costa Patagónica, División Colonia, Sección Gobierno, Sala IX, legajos 16.3.4 al 16.3.12, 16.4.4 y 16.4.5. Por último, también realizamos una confrontación crítica con otras fuentes editadas de los siglos XVIII y XIX, recurriendo asimismo a investigaciones históricas y etnohistóricas, de forma tal de controlar la información vertida en los relatos del Superintendente.

\section{ANTONIO VIEDMA Y LA COLONIZACIÓN DE LA COSTA PATAGÓNICA}

Hasta la fecha poco se sabe sobre la figura de este colonizador de la costa patagónica, quien tras su breve paso por la misma desapareció de las páginas de la historia colonial latinoamericana. Don Antonio de Viedma nació en el seno de una familia de ilustre abolengo de Jaén, España, teniendo como padres a Andrés Nicolás de Fernández Viedma y Narváez, regidor del cabildo de esa ciudad y doña Feliciana Verdejo y Fajardo. A su vez tuvo como hermanos a Andrés y Francisco de Viedma, que también jugaron un rol destacado en la colonización de la costa patagónica, especialmente el último quien fuera un experto en agricultura (Entraigas 1960). Los tres hermanos ingresaron a temprana edad a la marina y por su prestigio y méritos pronto atrajeron la atención del Rey Carlos III y sus ministros, quienes solicitarán sus servicios en el proyecto de colonización de la costa patagónica (Molina Martínez 1987).

Si bien la crisis de las relaciones hispanobritánicas llevaron a España -a partir de la segunda mitad del siglo XVIII- a preocuparse por la defensa y colonización de la costa atlántica patagónica (Ramos Pérez 1952); la salvaguarda de la soberanía española en el litoral del Atlántico Sur y su fomento económico, no fueron los únicos motivos que impulsaron la creación de las colonias patagónicas. Tal como se desprende de las investigaciones de Senatore (2002, 2004, 2005 y [2003] 2007), la singularidad del plan deviene del intento de fomentar en estas poblaciones un nuevo tipo de sociedad sobre la base de los ideales de la ilustración española, los cuales retomaremos mas adelante ya que resultan fundamentales para comprender la forma en que se estructuró el discurso de Antonio Viedma sobre el contacto.

De este modo, en 1778 el rey Carlos III promulgó una real cédula para la formación de una población en un puerto de la costa patagónica, ${ }^{2}$ hasta que finalmente fue decidida la fundación de cuatro enclaves poblacionales - de los cuales sólo se fundaron tres con proyección de permanencia en el tiempo-, debido al peligro que representaba el aislamiento de un único establecimiento (Destéfani 1984) -Figura 1. Para llevar adelante la fundación de las colonias patagónicas se designó a Juan de la Piedra como Comisario Superintendente de Río Negro y San Julián, y Antonio Viedma, como contador de ambos establecimientos. Sin embargo, de la Piedra hizo abandono de sus funciones, fue procesado y sustituido por Francisco Viedma. A su vez, el 7 de agosto de 1779 quedó desdoblada la jurisdicción al ser designado el teniente de navío Andrés de Viedma Comisario Superintendente de la Bahía de San Julián (De Paula 1984). En ello pesó la decisión del Virrey Vértiz, quien consideró variar los destinos de los contadores-tesoreros, para evitar que los hermanos Viedma -Francisco y Antonio- estuviesen juntos en Bahía Sin Fondo (Gorla 1984). Sin embargo, el progresivo deterioro en la salud mental de Andrés de Viedma, llevará a que sea separado de su comisión en San Julián, recayendo ésta, finalmente, en manos de su hermano Antonio.

Durante el transcurso de 1779 se fundan los dos primeros establecimientos: el Fuerte San José o La Candelaria y el Fuerte Nuestra Señora del Carmen. El primero fue establecido en la Península de Valdés (Chubut), de carácter netamente militar. Durante su primer año de vida, la autoridad sobre el mismo pasará de las manos de Juan de la Piedra, a Francisco de Viedma, y de éste a su hermano Antonio, quien debió abandonar tempranamente el establecimiento a raíz del malestar generado por una grave epidemia de escorbuto entre los integrantes de la tropa allí destinada. La gravedad de la situación padecida en San José llevó a Antonio de Viedma a convocar una junta, siendo la opinión de todos de abandonar el fuerte. Sin embargo, Antonio de Viedma adujo que no estaba facultado para llevar a cabo tal resolución, actitud que llevó a la gente de armas a acabar con su autoridad. Incapaz de encontrar una solución, el $1^{\circ}$ de agosto de 1779 Viedma dejó el establecimiento en manos de un pequeño destacamento y se retiró a Montevideo a la espera de nuevas órdenes (De Paula 1984;

2 Archivo General de Indias [AGI], Buenos Aires, 326. 


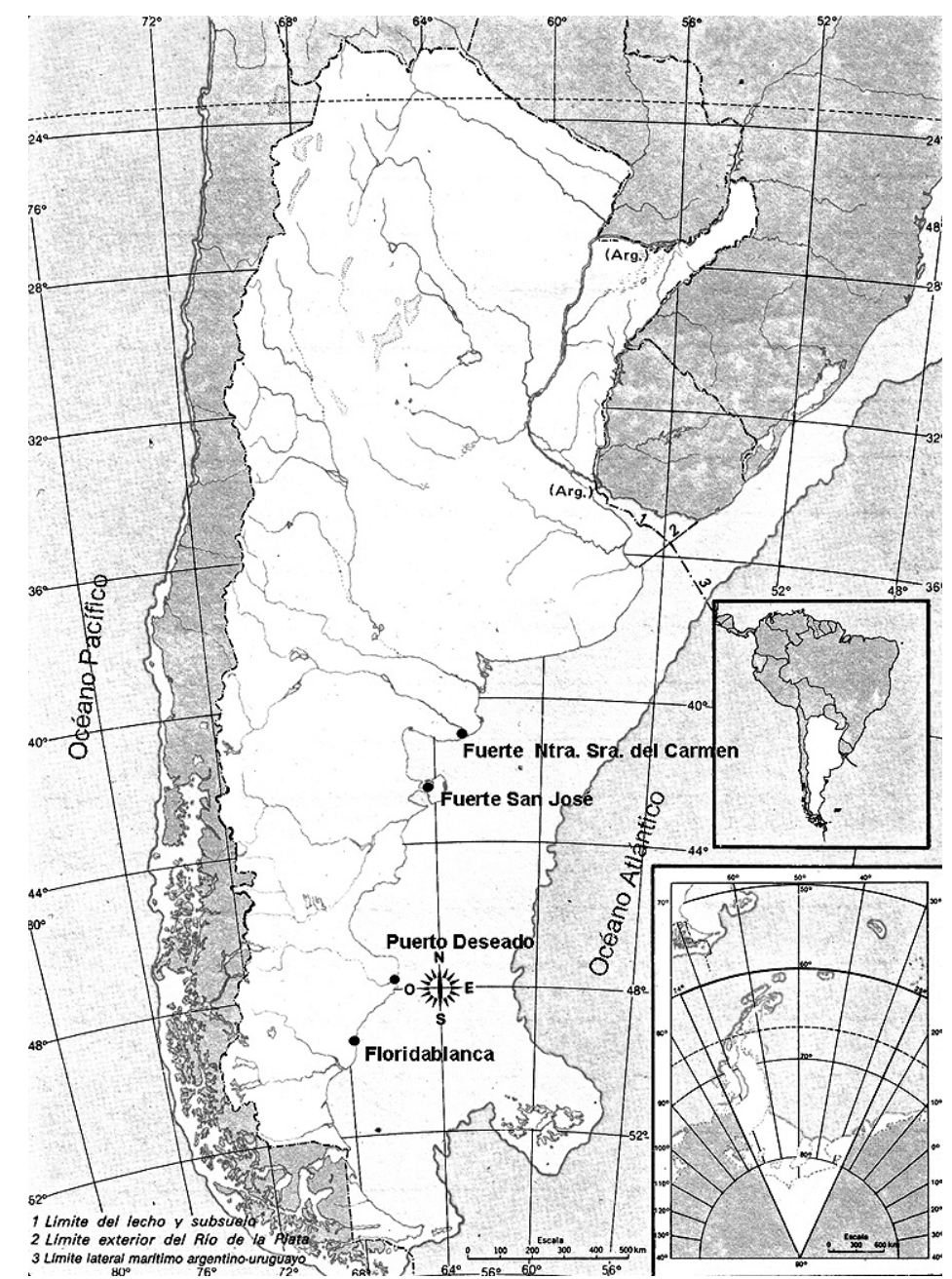

Fig. 1. Localización de los asentamientos fundados en el marco de la colonización española de la costa patagónica en el siglo XVIII en un mapa actual.

Destéfani 1984; Dumrauf 1992). En el transcurso de 1779 también se funda el Fuerte Nuestra Señora del Carmen (Carmen de Patagones, Buenos Aires), bajo el mando de Francisco de Viedma hasta 1784, destinado a convertirse en una próspera colonia agrícola y en el único establecimiento que sobrevivió de la empresa colonizadora.

Como vimos, el plan preveía la fundación de otro enclave en el área comprendida entre el puerto Santa Elena y el estrecho de Magallanes. La bahía de San Julián fue seleccionada como el lugar más indicado para ello, confiándose su jurisdicción a Antonio de Viedma, quien arriba a la bahía en marzo de 1780 en un plan de reconocimiento para evaluar un paraje adecuado para la fundación de una colonia (Viedma [1783] 1972a; De Paula 1984, Destéfani 1984). Permanecen en el puerto aproximadamente 20 días. Durante esta breve estadía se realizan exploraciones en búsqueda de fuentes agua dulce, recursos y, fundamentalmente, se establece el primer contacto con los indígenas locales de forma totalmente pacífica.

Como mediadores al principio funcionaron uno de los pilotos que acompañaban la expedición, José Ignacio de Goycochea -quien había tratado previamente con los indígenas de San Julián- y el Cacique Julián Grande -hermano del cacique principal Julián Gordo-, quien dominaba el castellano por haber pasado algún tiempo en Buenos Aires, pero receloso de los españoles. La población 
tehuelche fue la que suministró información sobre la disponibilidad de un manantial de agua dulce, cercano al lugar donde tenían emplazada la toldería, y que a fines de 1780, cuando regresa la expedición colonizadora a la costa de San Julián, será el elegido para la instalación de la colonia.

Con el objeto de reconocer el río Santa Cruz, Antonio de Viedma y la flota que lo acompaña continúan su exploración hacia el sur. Sin embargo, por condiciones climáticas adversas no pudieron ingresar, y continuaron rumbo a puerto Deseado, donde había abundancia de agua dulce para el suministro de la flota. Una vez allí se levantó un pequeño campamento para pasar el invierno y se intentó alguna siembra, con el fin de evaluar la calidad del terreno. Sin embargo, en esta ocasión Viedma tampoco se libró del azote del escorbuto, el cual ocasionó numerosas víctimas. El descontento general desembocó en una amenaza de sublevación, plasmada en un pasquín elaborado anónimamente por los enfermos y que clavaron en la puerta del rancho del superintendente, haciendo tambalear su autoridad. Ante este grave episodio, el funcionario decidió enviar a todos los enfermos y descontentos a Buenos Aires, quedándose con una pequeña dotación hasta el momento de regresar a
San Julián para fundar la colonia de Floridablanca, puerto seleccionado por ofrecer mejores posibilidades para la agricultura (De Paula 1984: 335; Senatore [2003] 2007).

\section{LA NUEVA POBLACIÓN Y FUERTE DE FLORIDABLANCA}

La fundación de Floridablanca tuvo lugar en noviembre de 1780 , siendo su localización definitiva el paraje sugerido por los tehuelches en abril de 1780 situado aproximadamente a unos $10 \mathrm{~km}$ de la costa. En la elección prevaleció la disponibilidad de fuentes de agua dulce para el riego de los campos de cultivo, así como la de tierra fértil y leña esenciales para la subsistencia de la colonia. Con una población inicial de 150 personas entre familias de labradores trasladados directamente desde España, funcionarios de la corona, tropa, maestranza y presidiarios, la colonia se fue construyendo poco a poco, de lo que dan testimonio la historia y la arqueología (Bianchi Villelli et al. 2005, Buscaglia et al. 2005; Senatore [2003] 2007; Senatore et al. 2007). Así, además de un fuerte -donde inicialmente se alojó toda la población- el poblado fue creciendo con la edifica-

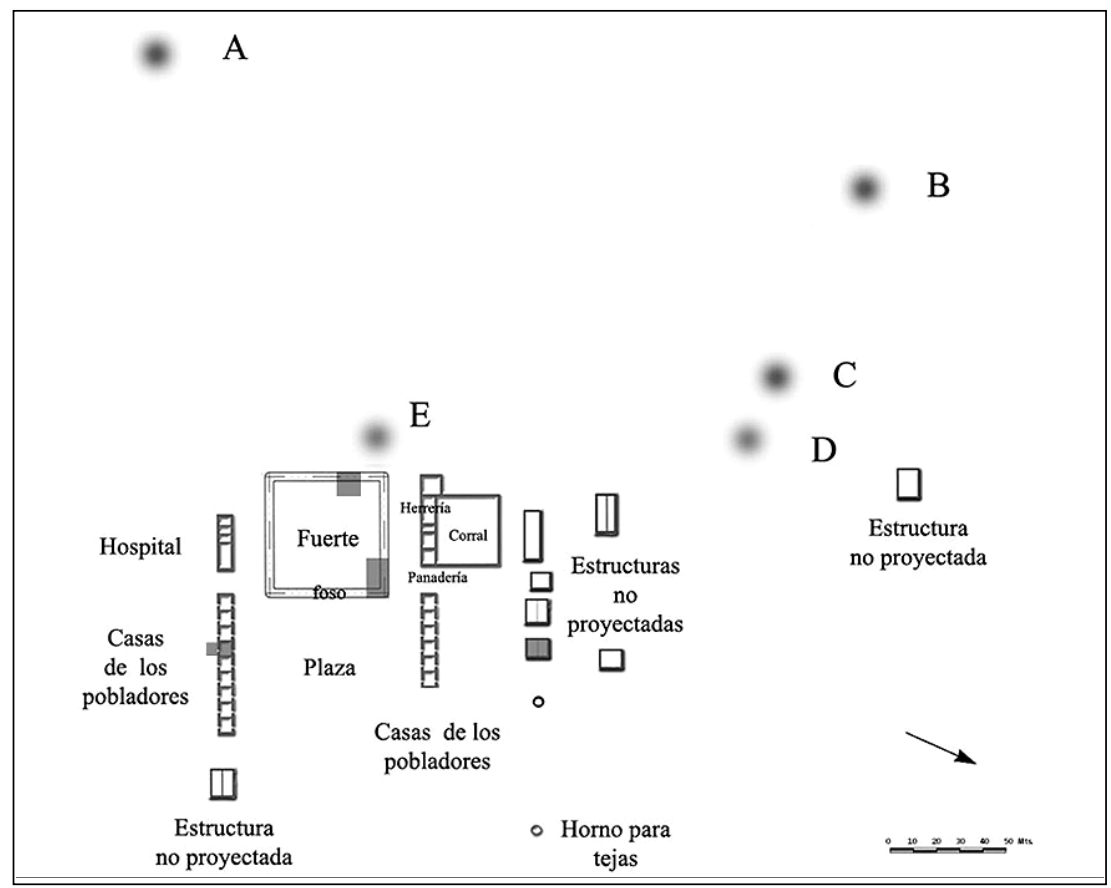

Fig. 2. Plano arqueológico de la "Nueva Colonia y Fuerte de Floridablanca. Los sectores sombreados en gris y los círculos -A, B, C, D y E-corresponden a las concentraciones en superficie con materiales indígenas y españoles asociados. 
ción de viviendas para las familias de labradores, un hospital, una panadería, una herrería, corrales para el ganado, un horno para cocer tejas y ladrillos financiados por la Corona, así como pulperías, cocinas colectivas y viviendas costeadas por individuos particulares. La colonia subsistió hasta principios de 1784, siendo la única de las fundaciones en las que se hizo efectiva una orden real que disponía el abandono de la costa patagónica.

\section{Una sociedad ordenada y controlada}

Como ya mencionamos, la singularidad del plan de poblamiento de la costa patagónica se relacionó con el intento de fomentar en estas poblaciones un nuevo tipo de sociedad sobre la base de los ideales de la Ilustración española. Los discursos ilustrados (Punta 1998) y las reformas borbónicas (Lynch 1992) representaron un intento de solución para dos de los problemas fundamentales que aquejaban a la España de la segunda mitad del siglo XVIII: los privilegios y la propiedad de la tierra (Senatore [2003] 2007). La mentalidad ilustrada consideraba que en estos factores residían las principales razones del atraso de España, de ahí que la utilidad -exaltación del valor del trabajo y condena del ocio- se convirtiera en el principio rector para alcanzar la prosperidad de la nación en el programa de reforma impulsado por el rey Carlos III y sus ministros (Chiaramonte 1962 y 1977; Rodríguez Díaz 1975; Sarrailh 1992; Senatore [2003] 2007).

Así, los ilustrados se propusieron convertir a la agricultura en el motor principal para el progreso del país, proporcionar a los vasallos condiciones iniciales de equidad para el aprovechamiento de la tierra, hacer de la familia conyugal el pilar de la sociedad, fomentar el valor del trabajo y las buenas costumbres entre la población (Senatore [2003] 2007). El concepto de una "población útil", productiva en el amplio sentido de la palabra, libre de los perjuicios derivados del ocio y las malas costumbres, fue la piedra basal para poner en práctica dicho modelo y garantizar el éxito de la empresa de poblamiento.

Dentro de este marco, el análisis de la construcción discursiva sobre la colonia Floridablanca muestra una imagen donde las recurrencias se articulan en torno al orden, el control y la armonía, posiblemente a partir de un recorte de la realidad. La congruencia entre la construcción narrativa y material acerca del poblado, tiende a reforzar esta estrategia en tanto demostración de la efectividad de las autoridades de la colonia para poner en práctica el plan. Sin embargo, también observamos discordancias entre la imagen que transmiten los documentos y la materialidad en el poblado, donde todo aquello que no encaja con el plan se omite o se desdibuja en el plano discursivo en pos de crear una imagen coherente con el proyecto y a través del cual el poder colonial legitima su fuerza y su eficacia (Senatore 2004, [2003] 2007; Senatore et al. 2005, 2007 y 2008; Bianchi Villelli 2007 y 2009; Bianchi Villelli et al. 2005; Marschoff [2004] 2007 y 2010; Buscaglia 2008, 2009 y 2010; Buscaglia et al. 2005 y 2008; Nuviala 2008; Bosoni 2010; entre otros). Es en relación a esta imagen ilusoria de un mundo ordenado y controlado que nos preguntamos por las implicancias que tuvieron las prácticas de los tehuelches en relación a la instrumentación del modelo de orden social en Floridablanca.

\section{CARACTERIZACIÓN GENERAL DE LAS RELACIONES INTERÉTNICAS EN FLORIDABLANCA}

El primer contacto sistemático, pacífico y sostenido en el tiempo entre indígenas y europeos en la bahía de San Julián tiene lugar con la fundación de la colonia de Floridablanca a fines del siglo XVIII. En siglos anteriores las relaciones fueron de índole esporádica y oscilaron entre hostiles y pacíficas tal como se sintetiza en la Tabla 1.

Durante sus cuatro años de funcionamiento la relación entre el poblado y los indígenas fue pacífica, fundamentalmente debido a la situación de aislamiento geográfico en la que se encontraba la colonia, ya que una relación hostil con los nativos probablemente habría implicado el fracaso del proyecto colonizador, dado el escaso apoyo que recibían las colonias desde la administración virreinal. En el caso de Floridablanca, por ejemplo, el aislamiento, el número reducido de población y tropa junto con el desabastecimiento colocaron a la colonia en una posición de inferioridad respecto a las poblaciones indígenas locales. Desde un principio los tehuelches fueron quienes sugirieron el mejor paraje para la instalación del poblado, aportaron valiosa información sobre los recursos locales y abastecieron con carne de guanaco a la población española durante períodos en 
Tabla 1. Caracterización del contacto a lo largo del tiempo en el área de la Bahía de San Julián (Narbourugh et al. 1694; Morris [1740-1746] s/f; Anson [1749] 1853; Fletcher 1854; Barne 1969; Lozano [1745] 1972; Viedma [1783] 1972a; Pigafetta 2001).

\begin{tabular}{|c|c|c|c|c|c|c|}
\hline & $\begin{array}{l}\text { Período } \\
\text { (siglos) }\end{array}$ & Viajeros & $\begin{array}{c}\text { Escenario } \\
\text { del } \\
\text { Contacto }\end{array}$ & $\begin{array}{l}\text { Tiempo de } \\
\text { Permanencia }\end{array}$ & Objetivos del Viaje & Forma de Contacto \\
\hline \multirow[t]{2}{*}{ XVI } & $\begin{array}{c}1520 \\
\text { (marzo-agosto) }\end{array}$ & Magallanes & Costa e Islas & 5 meses & Exploración & $\begin{array}{c}\text { Directo } \\
\text { (predominantemente } \\
\text { etnocéntrica y } \\
\text { encuentros violentos) }\end{array}$ \\
\hline & $\begin{array}{c}1578 \\
\text { (junio-agosto) }\end{array}$ & Drake & Costa e Islas & 2 meses & Exploración & $\begin{array}{c}\text { Directo } \\
\text { (encuentros violentos) }\end{array}$ \\
\hline XVII & $\begin{array}{c}1670 \\
\text { (abril- } \\
\text { septiembre) }\end{array}$ & Narborough & Costa & 6 meses & $\begin{array}{l}\text { Exploración y } \\
\text { comercio }\end{array}$ & $\begin{array}{c}\text { Directo } \\
\text { (la población local se } \\
\text { mantuvo recelosa respecto } \\
\text { a los europeos) }\end{array}$ \\
\hline \multirow{4}{*}{ XVIII } & 1741 & Anson & Costa & 2 meses & Exploración & $\begin{array}{c}\text { No hubo contacto con } \\
\text { la población local }\end{array}$ \\
\hline & $\begin{array}{c}1745 \\
\text { (febrero) }\end{array}$ & $\begin{array}{c}\text { Padres Strobel } \\
\text { Cardiel y Quiroga }\end{array}$ & $\begin{array}{l}\text { Costa e } \\
\text { interior }\end{array}$ & 1 mes & $\begin{array}{c}\text { Exploración e } \\
\text { evangelización de las } \\
\text { poblaciones locales }\end{array}$ & $\begin{array}{l}\text { No hubo contacto con } \\
\text { la población local }\end{array}$ \\
\hline & $\begin{array}{c}1753 \\
\text { (enero-marzo } \\
\text { y noviembre) }\end{array}$ & Barne & Costa e Islas & $\begin{array}{l}2 \text { meses y } \\
\text { medio }\end{array}$ & $\begin{array}{l}\text { Explotación y } \\
\text { comercio de } \\
\text { recursos naturales }\end{array}$ & $\begin{array}{c}\text { Directo } \\
\text { (hostilidad al principio, } \\
\text { pero luego pacífico) }\end{array}$ \\
\hline & $1780-84$ & Viedma & $\begin{array}{l}\text { Costa e } \\
\text { interior }\end{array}$ & 4 años & Colonización & $\begin{array}{c}\text { Directo } \\
\text { (pacífico, al principio } \\
\text { en la costa y luego en el } \\
\text { escenario del poblado) }\end{array}$ \\
\hline
\end{tabular}

los que se interrumpió el envío de suministros desde el río de las Plata. Así, durante el funcionamiento de la colonia, los indígenas permanecieron durante períodos variables -entre unos pocos días y varios meses dependiendo de las rutinas y los traslados de la toldería- junto a la colonia, hecho avalado tanto por la información histórica como por el registro arqueológico (Sanguinetti et al. 2005; Buscaglia y Nuviala 2007; Buscaglia 2009 y 2010).

Por otro lado, es importante mencionar que los tehuelches de San Julián tenían acceso -a través del intercambio con otros grupos indígenas y españoles- a bienes europeos. ${ }^{3}$ Para este caso en

3 Si bien Viedma en su relato asegura que la población local de San Julián no tuvo contacto con españoles, aunque señala sus traslados hacia el norte, sur y oeste para intercambiar sus mantas de cuero o quillangos, plumas de ñandú, entre otras cosas por caballos y artículos manufacturados por otras comunidades u obtenidos por las mismas de los europeos ([1783] 1972b); sabemos por las cartas de su hermano Francisco que el grupo indígena de San Julián habría frecuentado el Fuerte Nuestra Señora del Carmen en 1779 , cerca de un año antes de la fundación de Floridablanca. particular, disponemos de referencias históricas que dan cuenta de movimientos estacionales realizados hacia el norte con el fin de intercambiar con otras comunidades indígenas y con los establecimientos de Nuestra Señora del Carmen y San José. ${ }^{4}$ Sin embargo, con la instalación de Floridablanca las visitas a los mismos se habrían reducido notoriamente, ya que la fundación de la colonia en su territorio permitía acceder a los indígenas de forma directa a los productos de origen europeo y criollo, muchos de ellos altamente valorados para reforzar el prestigio y el poder tanto dentro como fuera del grupo, mediante mecanismos de apropiación, redistribución e intercambio. Al respecto es elocuente la observación que en 1783 realiza el Piloto Basilio Villarino: En este río (Río Negro) se hallaron estos indios con los

4 AGN, Sala IX, 16.3.2 "Carta de F. Viedma a J. J. Vértiz, Fuerte Nuestra Señora del Carmen, 4 de junio de 1779"; Sala IX, 16.4.5 "Carta de F. Lucero a T. Gil (Capitán del Regimiento de Infantería de Buenos Aires y Gobernador de Río Negro), Puerto San José, 4 de junio de 1788"; "Carta de P. Burniño a T. Gil, Fuerte del Carmen, 11 de junio de 1788" y Viedma [1783] 1972, entre otros. 
tehuelches de San Julián, con los cuales hicieron mucho comercio, porque venían muy ricos con las alhajas que les habían regalado los cristianos de aquel establecimiento (Villarino 1972: 1123).

Es importante destacar aquí, que fue variable la forma en que se estructuraron las relaciones interétnicas entre un mismo grupo indígena y cada uno de los asentamientos que formaron parte del proyecto de poblamiento de la costa patagónica. A diferencia del caso de Floridablanca, la relación de los tehuelches de San Julián con los otros dos poblados no siempre fue pacífica.

La antítesis al modelo de orden social:

las prácticas y costumbres tehuelches

En este apartado caracterizamos brevemente la población tehuelche que interactuó con la colonia de Floridablanca, en función de la particularidad de sus prácticas, en tanto alternativas sociales diferentes al modelo de sociedad que se buscó fomentar en el asentamiento español. Nos centraremos en aspectos genéricos de la sociedad tehuelche, haciendo un especial hincapié en aquellas prácticas de carácter más cotidiano. No pretendemos realizar un análisis exhaustivo de las mismas, ya que el mismo excede los objetivos y los límites de este trabajo. Simplemente nos interesa describir a un nivel muy general las prácticas cotidianas de los tehuelches en función de las diferencias que existían entre su sociedad y el ideal que se buscaba fomentar desde el proyecto colonizador. La principal fuente de información con la que trabajamos es la Descripción de la costa meridional del Sur llamada vulgarmente Patagonia... de Antonio de Viedma ([1783] 1972b). Asimismo, recurrimos a la confrontación crítica con otras fuentes éditas de los siglos XVIII y XIX relativas al contacto con tehuelches en Patagonia centro-meridional, a estudios históricos y etnohistóricos, de forma tal de controlar la información vertida en el relato del superintendente y completar el panorama sobre las prácticas indígenas.

Una de las diferencias más sustanciales con respecto a la población hispano-criolla sustentada en un modelo agrícola y sedentario habría sido un modo de subsistencia basado en la caza-recolección y el nomadismo. Asimismo, el modo de subsistencia y la movilidad incidieron directamente sobre los procesos de fragmentación y reagrupamiento de distintos segmentos de la población indígena, donde la cohesión y el nucleamiento social por períodos prolongados de tiempo y en escenarios fijos, carecieron de relevancia. En Floridablanca, por el contrario, la fijeza espacio-temporal y sus significados asociados actuaron como mecanismos fundamentales en el ordenamiento social y en la creación de rutinas acordes a las prácticas que buscaba fomentar el proyecto colonizador. Como señala Giddens (1976), la repetición en el uso de un escenario es un factor de importancia en la fijación de una interacción y una rutina social.

Los tehuelches tenían una gran disponibilidad de tiempo libre; entre sus actividades de esparcimiento se encontraban el juego -naipes, dados, piedritas, tabas, etc.-, diversos pasatiempos-carreras ecuestres, competencias de fuerza física, juegos de pelota, etc. - y el consumo de estimulantes como el tabaco y el alcohol, implicando muchas de ellas un alto grado de socialización (Viedma [1783] 1972b; Malaspina [1789-1795] 1938; D’Orbigny [1835-1847] 1999; Bourne [1853] 1998; Musters [1871] 1997; Coan [1880] 2006; Martinic 1995, entre otros). Esto de alguna manera entraba en contradicción con la inculcación de rutinas, la moral del trabajo y la crítica a la holgazanería, fundamentos esenciales para el fomento de poblaciones útiles en las colonias patagónicas. Asimismo, actividades similares en las colonias fueron reglamentadas y penadas, ya que los administradores consideraban que eran causantes del desorden moral y social en los poblados, y por lo tanto contraproducentes para su fomento (Gorla 1984).

La poligamia, la tolerancia del adulterio y la permisividad sexual (Viedma [1783] 1972b; Fitz Roy 1839; Musters [1871] 1997; Coan [1880] 2006; Martinic 1995 y 2008, Lista 1998, entre otros) fueron prácticas comunes a los tehuelches. Al respecto Viedma describiendo la conducta sexual abierta de las mujeres indígenas expresa lo siguiente: [...] interin son mozas y tienen esperanza de casarse guardan la virginidad; pero en perdiendo aquella esperanza, se entregan a todos [...] (Viedma [1783] 1972b: 952) o cuando refiriéndose a la vida dentro del toldo señala: Las doncellas aquí sin embargo de esta ocasión, procuran, como queda dicho, guardar su virginidad, mientras tienen esperanza de casarse, pero si llegan a perderla se dan a cualquiera, y tanto ellas como las viudas pasan buena 
noche, acomodándose indistintamente con el que primero se les acerca a dormir con ellas (Viedma [1783] 1972b: 962). Incluso, cuando el referido autor describe las prácticas de los hechiceros, no deja de notar que: [...] siempre sobran pretendientes para este empleo, porque tiene facultades de usar de las mujeres de los indios, si ellas consienten, o de ellos, si el hechicero es mujer (Viedma [1783] 1972b: 955). Seguramente éstas fueron prácticas que entraron en contradicción con la moral cristiana que se habría buscado fomentar en los emprendimientos coloniales de España. En los establecimientos patagónicos se impusieron prohibiciones expresas, so pena de castigo, para los tratos ilícitos entre colonos y mujeres indígenas (Gorla 1984).

Si bien estas son sólo algunas de las principales diferencias que logramos individualizar entre las prácticas tehuelches y aquellas que se buscaba fomentar desde el proyecto colonizador en función del principio de utilidad de las poblaciones; no obstante somos conscientes que existieron diferencias aún más sustanciales en relación a las esfera secular y religiosa, con sus ritos y ceremonias; las normas sociales; la medicina, la cultura material; la apariencia y la imagen personal -sobre todo en lo que hace a la vestimenta y la pintura corporal-, los hábitos alimentarios, entre otras cosas. Las cuales a los ojos del grueso de la población de la colonia, sobre todo aquella procedente de España, habrían resultado completamente extrañas y novedosas, provocando posiblemente reacciones encontradas de rechazo, curiosidad y/o aceptación.

Por lo tanto, más allá de las evidentes diferencias culturales entre los tehuelches y la población hispano-criolla, como vimos muchas de las prácticas que formaban parte de la vida cotidiana de los indígenas representaban una antítesis al ideal de población útil y a la moral que se buscaba fomentar desde el proyecto colonizador. De este modo, cabe preguntarse si la dinámica social de la colonia se planificó en función de los ideales del proyecto, ¿cómo se configuraron las relaciones entre indígenas y españoles en el devenir de la vida cotidiana? y ¿cuáles fueron sus implicancias en términos del ideal de sociedad que se buscó fomentar en la colonia? Autores como Sahlins (1981, 1985, 1995), Lightfoot et al. (1998) y Bourdieu (1999) han subrayado cómo los encuentros coloniales crean un espacio de apertura y concientización de los esquemas subliminales que gobiernan el habitus y las prácticas de los actores involucrados en el encuentro, posibilitando con ello la redefinición del orden cultural en el transcurso de la vida cotidiana. Sin embargo, la interacción con la población indígena y muchas de sus costumbres, podrían haber representado a los ojos de los responsables de la puesta en práctica del plan un peligro de contaminación del ideal de sociedad que se buscaba fomentar en Floridablanca.

\section{LAS RELACIONES INTERÉTNICAS EN LA DIMENSIÓN DISCURSIVA}

En esta sección se analiza cómo se construyeron y representaron las relaciones interétnicas en el plano del discurso de Antonio de Viedma. Ello resultó importante para establecer la imagen transmitida por la documentación histórica en función de las prácticas tehuelches caracterizadas previamente y del ideal de sociedad subyacente al proyecto de poblamiento, en particular atendiendo al principio de población útil.

En el contexto de las colonias, la documentación escrita fue generada casi exclusivamente por funcionarios insertos en diferentes esferas del poder colonial, de ahí que pueda ser entendida, como señala Senatore ([2003] 2007), como un instrumento de orden y administración. Nuestra aproximación al estudio de los documentos buscó identificar e interpretar el significado de constantes que pudieran aparecer en el plano discursivo, tales como recurrencias en ciertas formas de enunciación respecto a las relaciones interétnicas. Así, el abordaje se articuló en torno a cinco ejes analíticos: 1) la forma en que se representa el carácter de las relaciones interétnicas; 2) los escenarios y los tiempos en los que se despliegan; 3) los actores; 4) las prácticas representadas y 5) el rol de la cultura material en el marco de la interacción entre la población indígena y la colonia.

Así, el análisis del discurso sobre el contacto en Floridablanca permitió identificar, en términos generales, una imagen ambivalente, de convivencia estrecha, amistosa pero también circunscrita. La misma se define en base a una serie de recurrencias y omisiones en el plano discursivo que serán desarrolladas a continuación en función de los ejes analíticos arriba mencionados. 


\section{El carácter de las relaciones interétnicas}

Nuestro primer interrogante acerca de la forma en que se construyeron y representaron las relaciones interétnicas en el plano discursivo se vincula a la forma en que son caracterizadas las mismas. Ello es importante no sólo para establecer cómo fueron en Floridablanca, sino también para dilucidar la imagen que Viedma buscó transmitir sobre las mismas. El análisis de la documentación histórica permitió identificar un trayecto temático común asociado al carácter pacífico de la interacción desde que se funda la población hasta que se produce el abandono de Floridablanca.

El 24 de marzo de 1780 la expedición arriba a las costas de San Julián con el objeto de efectuar un reconocimiento y evaluar un paraje adecuado para la fundación de una colonia. Permanecen en el puerto aproximadamente 20 días. Durante esta breve estadía se realizan exploraciones en búsqueda de fuentes de agua dulce, recursos y, fundamentalmente, se establece el primer contacto con los indígenas locales, quienes espontáneamente se presentaron en la costa y se interactuó pacíficamente. El grupo tehuelche suministró información sobre la disponibilidad de un manantial de agua dulce, cercano al lugar donde tenían emplazada la toldería ${ }^{5}$ y que a fines de 1780 , cuando regresa la expedición colonizadora, será el elegido para la instalación de la colonia

Llamativamente durante los cuatro años de funcionamiento de la colonia, ni el diario de Viedma ni las cartas escritas por este funcionario y dirigidas al Virrey, muestran indicios acerca de episodios de hostilidad o conflictos entre la colonia y la población indígena, salvo en dos casos donde se registraron incidentes menores. El primero se produce al arribo de la expedición en marzo de 1780 y tiene como protagonista al cacique Julián Grande, como mostramos a continuación: Al amanecer llegaron los de la lancha y bote con la sal, y dijeron que el cacique Julián Grande (este es el que estuvo en

5 El manantial se encontraba aproximadamente entre 2,5 y 3 leguas de la playa, unos 10,5 o 12,6 km. Destacamos que 30 años antes de la instalación de Floridablanca en San Julián, el piloto Jorge Barne consignó exactamente la misma distancia para la ubicación de las tolderías de los indígenas de la localidad, incluso señaló la presencia del agua (Barne 1969). Estos datos podrían estar dando cuenta de cierta redundancia ocupacional de las poblaciones indígenas a lo largo del tiempo en la bahía de San Julián.
Buenos Aires), les había salido al encuentro con su gente, quitándoles los sacos, sin permitirles traer la sal; y que al ponerse el sol llegó Julián Gordo (el otro cacique), y riñendo a aquél su acción, dijo a la gente se embarcase y me trajesen cuanta sal quisiesen, que yo era su amigo. A las nueve se presentaron los indios en la playa. Los caciques vinieron a bordo, donde acaricié al uno, y reñí al otro: este quedó como atemorizado, y el otro muy contento me dio a entender le quería mal, porque era muy hablador. Esta tarde no pudimos salir del Puerto por estar el tiempo aturbonado (Viedma [1783] 1972a: 885-886).

El segundo caso tuvo lugar en el contexto de la colonia, pero en el que Superintendente resarce de cualquier culpabilidad a los indígenas, al desconfiar de las intenciones del poblador que realiza la acusación, como citamos a continuación: [...] Pocos días hace que el tonelero Francisco Alonso me dijo que los indios le habían hurtado las principales herramientas de su ejercicio y por cuya causa no podría trabajar en él; he procurado con el cacique haga las diligencias posibles para buscarlas pero no las ha encontrado, por cuya causa me juzgo ha sido tramoya del mismo tonelero con el fin de que lo mande a esa misma provincia lo que ejecuto remitiéndolo en el Paquebote San Sebastián en vista de que no trabaja en su ejercicio, lo que hago presente a VE y para que se digne mandar venga otro en su reemplazo pues hace notable falta. ${ }^{6}$

Una constante en la construcción discursiva sobre el contacto del superintendente es una imagen de los indígenas como bondadosos, generosos y "obedientes". Esta imagen perdurará y permeará la conceptualización del contacto en la bahía de San Julián, aún tiempo después del abandono de la colonia, como se expresa en la siguiente carta: Los robustos Indios que habitan los parajes de la costa patagónica más a propósito, nunca han desmentido la sinceridad de su afecto hacia nosotros, porque las primeras embarcaciones que arribaron en estos últimos tiempos tuvieron una acogida admirable; después cuando por cuenta de la Real Hacienda formó establecimiento Don Antonio Viedma para abandonarlo, como se le previno, tuvo necesidad de engañarlos y embarcarse con su gente de noche

6 AGN, Sala IX, 16.3.8 "Carta de A. Viedma a J. J. Vértiz, Floridablanca, 5 de octubre de 1781". 
temeroso de que le estorbarán la salida, que les era muy sensible [...] (Romero [1788] 1939).

Un caso bastante diferente fue por ejemplo el del Fuerte Nuestra Señora del Carmen, comandado en un principio por Francisco de Viedma. En los relatos de este último, no sólo parece ofrecerse una imagen más realista del contacto, aunque también más etnocéntrica, en tanto se hace mención a una mayor cantidad de episodios de conflictos con las poblaciones locales (Luiz 2006; Nacuzzi 2002, 2005). En algunos de estos casos los protagonistas habrían sido los mismos tehuelches de San Julián, durante sus traslados hacia el norte -antes de la fundación de Floridablanca- y luego de su abandono.

Por ejemplo, en un informe de Francisco de Viedma fechado el 4 de junio de 1779 y dirigido al virrey Vértiz, se relatan los acontecimientos de los primeros 45 días de su estadía en el río Negro. Allí aparecen referidos los primeros contactos de Viedma con indígenas patagónicos, entre los que se cuentan los tehuelches de San Julián y con los cuales se produjeron algunas fricciones durante el contacto inicial, como observamos en un pasaje del referido informe: [...] Los indios que se han presentado en este paraje son como llevo dicho de Nación Tihuelchu y Pampas, aquellos oriundos de San Julián, y de estos terrenos, y el Río Colorado. El cacique de más séquito de los primeros es un mozo que le llaman Julián hijo según me ha informado Goycochea de otro Julián que estuvo en esas ciudad de Buenos Aires años pasados, manifiesta buena índole, pero los suyos no han dado muestras de tanto sosiego como los Pampas, pues nos han hecho tomar las armas si bien solamente para manifestar las fuerzas, e infundirles algún temor que los sosegase de algunas leves acciones que se advirtieron, las que quedaron ahogadas al principio aunque fue causa de que levantasen sus tolderías que tenían inmediato al fuerte que se está haciendo, y caminasen a sus tierras, en cuya retirada también intentaron algunos de ellos asaltar a 12 hombres que tenía en una Isla cortando madera 3 leguas de distancia, pero todo se cortó por las precauciones que se tomaron cuyos acaecimientos no particularizo por no dilatarme y no ser sustanciales [...]. ${ }^{7}$

7 AGN, Sala IX, 16.3.2 "Carta de F. Viedma a J. J. Vértiz, Fuerte del Carmen, 4 de junio de 1779".
Entre 1787 y 1788 , poco tiempo después del abandono de Floridablanca, las relaciones entre los indígenas de San Julián y los establecimientos patagónicos se vuelven cada vez más tensas. El cacique Julián Camelo y su indiada son acusados de producir distintas acciones, como por ejemplo el robo de ganado tanto en el Fuerte San José ${ }^{8}$ como en el Fuerte Nuestra Señora del Carmen. ${ }^{9}$ Finalmente en 1788, un episodio casi intrascendente ocurrido en puerto San José, donde la poca satisfacción que mostró el cacique Julián y sus cinco acompañantes ante el obsequio que se les hizo, generó la desconfianza del comandante del establecimiento, ordenando su captura y traslado al

8 Durante este episodio, ocurrido en 1787 en las inmediaciones del Fuerte San José y la Estancia del Rey, en Puerto San José (Península de Valdés, Pcia. de Chubut), en un documento se menciona el asesinato de un pistoletazo del cacique Julián, aunque no se proporcionan más precisiones al respecto, ya que el autor del hecho, presuponía que se trataba de dicho cacique, razón por la cual no estamos tan seguros de que se tratase de él. Incluso el comandante del Fuerte San José en su relato sobre los hechos menciona que cuando le trajeron la cabeza del cacique :...y por lo desfigurada que estaba no pude conocer si era la del Cacique Julián, pero creo que será la de él por haberle visto igual recado de montar, y por el modo de accionar de que me informó el que lo mató (AGN, Sala IX, 16.4.4. "Carta de P. Burriño a J. I. de la Quintana, Fuerte de la Candelaria en Puerto San José, 7 de agosto de 1787”). Finalmente, como señala Nacuzzi (2005) en una declaración tomada a un indígena perteneciente a la gente de Julián, no hace mención a que su cacique haya muerto cuando le preguntan quiénes participaron de distintos ataques y robos, aunque da nombres de caciques y de indios que participaron. A una de las preguntas responde afirmando que: un indio que mataron últimamente en San José se llamaba Guetechunque, siendo éste al parecer el que confundieron con Julián los del Fuerte San José (AGN, Sala IX, 16.4.4 "Declaración tomada al Indio Carlos, alias Juancho, dependiente del Cacique Julián Camelo, por el Teniente de Infantería Lázaro Gómez... Fuerte del Carmen, 2 de septiembre de 1787").

9 En este caso, ocurrido durante 1786 en las inmediaciones del Fuerte Nuestra Señora del Carmen, Julián Camelo, sus indios $y$ otros caciques son acusados de la muerte de un poblador, de un soldado y del robo de ganado. En la declaración mencionada en la nota anterior, el indígena mismo niega que el Cacique Julián haya intervenido directamente en dichas acciones. Sin embargo, en un documento del año siguiente, vuelven a recaer las acusaciones sobre el cacique Julián respecto a este episodio, aunque él niega su participación endilgando la culpabilidad a un hermano suyo (AGN, Sala IX, 16.4.5. "Carta de F. Lucero a T. Gil, Puerto San José, 4 de junio de 1788”). 
Fuerte del Carmen. ${ }^{10}$ Durante el trayecto en barco, el cacique y otro indígena se fugaron, lo que terminó con el asesinato del primero y la captura del segundo a manos de los españoles, en un excesivo acto de represalia. ${ }^{11}$

Hemos de notar que los acontecimientos suscitados entre los indígenas de San Julián y los establecimientos situados al norte de Floridablanca, muestran el carácter variable de las relaciones interétnicas entre un mismo grupo indígena y las tres poblaciones fundadas en el marco de un mismo plan, y hasta comandadas por funcionarios directamente emparentados. No podemos dejar de señalar que los episodios de hostilidad claramente se producen antes de la creación de Floridablanca y luego de su abandono, pero nunca mientras esta funcionó, al menos de acuerdo a la documentación relevada hasta el momento.

Ahora bien, ¿por qué existe un contraste tan marcado en la estructuración del contacto entre la población indígena de San Julián, Floridablanca y los otros dos poblados? Para responder a ello pensamos que es necesario entender la singularidad y las características de cada uno de los contextos, ${ }^{12}$ las estrategias y los intereses tanto de los indígenas como de los comandantes de los establecimientos y su gente, y por qué no la personalidad, experiencia de los mismos y su predisposición para interactuar con las poblaciones locales.

10 AGN, Sala IX, 16.4.5. "Carta de F. Lucero a T. Gil, Puerto San José, 4 de junio de 1788" y Carta dirigida al Comandante del Establecimiento de Río Negro, 30 de julio de 1788 (sin remitente y lugar).

11 AGN, Sala IX, 16.4.5 "Sumaria información hecha a fin de averiguar en quien recae la omisión de haber hecho fuga el diez de junio después de puesto el Sol, el Cacique Julián y otro Indio en la boca del Río Negro, desde el borde del Bergantín Nuestra Señora de la Piedad, que los conducía presos, y encargados el subteniente de Infantería de Buenos Aires, Don Bernardo Durán, por Don Francisco Lucero, teniente de dicho Regimiento y Comandante del Establecimiento de San José en la costa Patagónica, Fuerte del Carmen, 11 de junio de 1788" y "Carta de T. Gil al Virrey Loreto, Fuerte del Carmen, 20 de junio de 1788".

12 Con ello nos referimos a que la situación de los tres establecimientos fue diferente. En primer lugar, el Fuerte Nuestra Señora del Carmen y su dependiente, el Fuerte San José se encontraban más cercanos a la línea de fronteras, en contacto y usurpando territorios de una mayor diversidad de parcialidades étnicas -relacionadas entre sí tanto en función de alianzas como enemistades-y por ello
En el contexto de Floridablanca de ninguna manera negamos que las relaciones entre la colonia y los indígenas de San Julián hayan sido armoniosas y amistosas la mayor parte del tiempo; a pesar de la llamativa ausencia de referencias a conflictos, y sobre todo a aquellos que podrían haberse suscitado en el transcurso de la vida cotidiana. Una vez más, el Fuerte Nuestra Señora del Carmen en una prolífica fuente de ejemplos con respecto a la deserción y cautiverio de pobladores -tanto civiles como militares-entre los indios; asesinatos causados por rencillas entre colonos e indígenas; relaciones "prohibidas" entre indias y españoles; situaciones que provocaban la cólera de las autoridades quienes debían asegurar el orden y preservar la identidad de estas poblaciones que recién comenzaban (Gorla 1984; Nacuzzi 2002; Luiz 2006; Ratto 2007). En Floridablanca, en cambio, en la documentación no se hace referencia a este tipo de situaciones, por demás comunes en los emplazamientos coloniales. Esto por supuesto lleva a interrogarnos hasta que punto esta imagen fue fiel a la realidad.

Pensamos que este cuadro de orden, armonía y quizás, poco realista sobre las relaciones interétnicas, no deja de ser una representación elaborada en el marco de un discurso, en un plano intelectual y sobre todo destinado a una audiencia particular: las autoridades virreinales. Es en este punto donde nos detenemos y nos preguntamos acerca del significado de esta representación y su relación con la imagen

con mayores posibilidades a fricciones con los mismos, lo cual habría predispuesto a sus comandancias a adoptar posiciones más rígidas en su trato con las poblaciones locales. A esto se suma, que estos establecimientos, debido a su localización estratégica, se convirtieron con el tiempo y rápidamente, en centros de intercambio y comercio fundamentalmente el Fuerte el Carmen-, y sobre todo de producción de ganado vacuno y equino, que como sabemos eran recursos altamente valorados entre los indígenas de Pampa y Patagonia. En comparación, Floridablanca se encontraba en una situación muy marginal. Estaba alejada de los centros de poder, la única población indígena con la que se vinculó fue la de San Julián, no alcanzó nunca el estatus de un polo de atracción dentro de las esferas de intercambio y comercial tanto colonial como indígena, y sobre todo careció del recurso ganadero; el que por el contrario en muchas ocasiones fue suministrado por los indígenas. Si evaluamos la significación de la colonia desde un punto de vista estrictamente estratégico, para los indígenas de Patagonia habría representado un interés menor en función de las posibilidades que ofrecían las otras dos poblaciones. 
que se busca transmitir de la colonia en función de los ideales que enmarcaron su fundación. Por el momento dejaremos este interrogante abierto, ya que la respuesta al mismo depende de la suma de otros elementos en el transcurso del análisis.

\section{Los escenarios y los tiempos del contacto}

El segundo aspecto que nos interesa indagar se relaciona con los escenarios -tanto dentro de los límites del poblado como fuera del mismo-y los tiempos que marcaron el ritmo de las relaciones interétnicas. En términos generales, se observa que los escenarios y los tiempos del contacto siempre son referenciados de forma poco precisa o ambigua en el plano discursivo, sobre todo cuando los tehuelches estuvieron asentados junto a la colonia.

En las pocas ocasiones en que se menciona la relación entre la toldería y el poblado, el fuerte y el establecimiento aparecen como referentes espaciales para situar el emplazamiento del campamento indígena, en sus períodos de convivencia con la colonia (Viedma [1783] 1972a). Sin embargo, no es posible establecer con claridad si con "fuerte" se refiere al poblado en general o bien la estructura en particular. Asimismo, se omite informar cualquier relación entre puntos cardinales y la localización de la toldería, ya sea durante su permanencia junto a la colonia o cuando se alejaba de ella. A continuación citamos pasajes del diario de Viedma a modo de ejemplo:

\section{Junio 1782}

El día 7 llegó Julián con sus indios y puso sus toldos junto al fuerte [...] (Viedma [1783] 1972a: 923). ${ }^{13}$

\section{Enero 1783}

[...] Mandé a los indios se retirasen del establecimiento, haciéndoles ver que no tenía ya nada que poderles dar por entonces: y ellos lo ejecutaron sin violencia ni disgusto, situándose a unas 6 leguas, desde donde de cuando en cuando nos socorrían con carne de guanaco (Viedma [1783] 1972a: 934).

13 En una carta también se hacer referencia a la instalación de la toldería junto al fuerte el día 7 de mayo de 1781 (AGN, Sala IX, 16.3.7 "Carta de A. Viedma a J. J. Vértiz, Floridablanca, 10 de mayo de 1781").
Del análisis de las cartas y el diario surge un claro silencio respecto a los escenarios de interacción tanto dentro del poblado como fuera del mismo. La única referencia de la que disponemos corresponde a una carta de Viedma quien refiere: [...] el cacique Julián Gordo me tiene mucho afecto, cuando tienen los toldos aquí cerca no sale de mi cuarto. ${ }^{14}$ El cuarto o la habitación del superintendente, es la única referencia registrada hasta al momento respecto a escenarios específicos de interacción en el contexto de la colonia, la cual da cuenta además de una relación íntima y personalizada entre el cacique y el superintendente.

Si bien la dimensión arqueológica de las relaciones interétnicas en Floridablanca no es objeto del presente trabajo, no obstante es importante mencionar que las investigaciones realizadas han permitido establecer la presencia de ocupaciones indígenas contemporáneas a Floridablanca en cercanías a la colonia e incluso evidencias materiales asociadas a prácticas indígenas dentro del poblado desde los inicios del asentamiento hasta el abandono del mismo (para más información ver por ejemplo Sanguinetti et al. 2005; Buscaglia y Nuviala 2007; Buscaglia 2009 y 2010) -ver Figura 2.

Con respecto a la forma en que se representan los tiempos del contacto en el plano discursivo, cabe señalar que no existen indicios directos; como por ejemplo cuántos días o meses los indígenas permanecieron junto al poblado. Por el contrario, las referencias concretas a los tiempos tienen lugar cuando los indígenas se encuentran alejados de Floridablanca: [...] los indios marcharon por 4 meses hacia el norte a buscar o cambiar caballos por cueros con otros indios (Viedma [1783] 1972a: 919).

En términos generales el discurso de Viedma transmite la idea de que el contacto habría tenido un carácter cotidiano, al menos durante ciertos períodos, a pesar de la escasa información suministrada respecto a sus tiempos. Como mencionamos, los indicios que nos ofrecen los documentos son indirectos. Por esta razón, nos interesó reunir una serie de variables presentes en la documentación histórica, tales como la cronología, la localización de la toldería, presencias y ausencias de la misma

14 AGN, Sala IX, 16.3.7 "Carta de A. Viedma a J. J. Vértiz, Floridablanca, 10 de mayo de 1781". 
Tabla 2. Tiempos de convivencia entre Tehuelches y la colonia de Floridablanca durante los cuatros años de funcionamiento de la misma.

\begin{tabular}{|c|c|c|c|}
\hline Cronología & $\begin{array}{c}\text { Localización de } \\
\text { la Toldería }\end{array}$ & $\begin{array}{c}\text { Tiempos de permanencia } \\
\text { (presuntos y aproximados) }\end{array}$ & $\begin{array}{c}\text { Entregas del Almacén } \\
\text { a los “Indios" }\end{array}$ \\
\hline $\mathbf{1 7 8 0}$ & $\begin{array}{c}\text { Junto al campamento } \\
\text { provisional }\end{array}$ & $\begin{array}{c}\text { Dos meses (entre diciembre de } \\
1780 \text { y enero de } 1781)\end{array}$ & Sin información \\
\hline $\mathbf{1 7 8 1}$ & Junto al fuerte & 7 meses (enero y entre mayo y octubre) & Todo el año, excepto febrero \\
\hline $\mathbf{1 7 8 2}$ & Junto al fuerte & 7 meses (entre mayo y diciembre, & Todo el año, excepto mayo \\
\hline $\mathbf{1 7 8 3}$ & Sin información & Sin información & Sin información \\
\hline
\end{tabular}

y las entregas realizadas a los tehuelches, ${ }^{15}$ para reconstruir aunque sea parte del cuadro sobre la convivencia indígena-hispano criolla, en los cuatro años de Floridablanca -Tabla 2.

Como se observa en la Tabla 2, entre 1781 y 1782 la convivencia entre tehuelches y españoles fue particularmente más estrecha y durante períodos prolongados, en especial durante el invierno. Cabe señalar, que aún cuando el campamento indígena se encontraba a cierta distancia de Floridablanca, se mantuvo la relación con la colonia, como se infiere a partir de las entregas realizadas por el Almacén y ciertas alusiones presentes en los documentos.

Las ausencias prolongadas de la toldería están vinculadas a sus traslados hacia el norte y sur para establecer relaciones de intercambio. Estas ausencias se extendían por períodos que variaban entre 2 y 5 meses aproximadamente durante el verano/otoño. El año de 1783 fue particular por dos razones. La primera fue que la colonia sufrió desabastecimiento, lo cual se extendió a los suministros entregados a los tehuelches. Así, en enero de ese año Viedma le solicita a los mismos que se retirasen del establecimiento, pero aún desde la distancia - $25 \mathrm{~km}$ - abastecían a la colonia con carne de guanaco (Viedma [1783] 1972a: 934). En segundo lugar, durante este año se produce el relevamiento de Viedma por Félix Iriarte, con lo cual se hace un silencio respecto a la relación con los indígenas. ${ }^{16}$

15 Cabe aclarar que las entregas desde el Almacén, no siempre coinciden con la presencia de las tolderías en las inmediaciones de la colonia, aunque es posible que una parte del grupo se encontrara en sus cercanías, ya que era frecuente entre los tehuelches la fisión y el reagrupamiento en función de una diversidad de factores relacionados.

16 Lamentablemente, luego de que Antonio Viedma abandona Floridablanca, la documentación oficial generada por su sucesor, el capitán del Regimiento de Infantería de Buenos Aires, don Félix Iriarte es o bien escasa o se encuentra depositada en archivos aún no relevados.
De igual manera que en el caso de los escenarios, la ambigüedad y la omisión son las constantes principales en la forma en que son referenciados los tiempos del contacto. No obstante, a partir de la reunión de distintos fragmentos de información, indirectamente se infirió la posible convivencia cotidiana entre ambas poblaciones, durante períodos más o menos prolongados de tiempo. El efecto discursivo es por lo tanto el desdibujamiento, de una realidad que pudo haber afectado al funcionamiento de la colonia y no haber sido vista con buenos ojos desde las esferas superiores de la administración colonial.

\section{Los protagonistas del contacto}

Las narrativas sobre el contacto muestran una recurrencia en la enunciación de los protagonistas y mediadores del encuentro: los individuos de mayor jerarquía y poder en ambos grupos. Así, el cacique Julián entre los tehuelches y el superintendente Antonio de Viedma entre los españoles, son los actores principales en el discurso oficial generado en torno al contacto. ${ }^{17}$ De esta manera, la diferencia cultural es superada mediante la elección de una estrategia de reconocimiento en la equivalencia de rangos y género entre los interlocutores principales de ambos grupos, donde el juego dinámico de identidades es lo que permite entablar las negociaciones en un escenario marcado por la diversidad sociocultural..$^{18}$

17 AGN, Sala IX, 16.3.7 "Carta de A. Viedma a J. J. Vértiz, Floridablanca, 10 de mayo de 1781" y "Carta de A. Viedma a J. J. Vértiz, Floridablanca, 13 de mayo de 1781"

18 Varios autores (Jones 1997 y 1999; Meskell 2001; Rothschild 2003, entre otros) han planteado que en el proceso de construcción de las relaciones sociales entran en juego las distintas identidades sociales que poseen los individuos, entendidas éstas como dinámicas y contextualmente específicas. 
Por otro lado, indicios acerca del carácter amistoso, fiel, fraternal e íntimo de las relaciones entre el cacique y el funcionario están presentes de manera dispersa en las narrativas producidas por este último como ejemplificamos a continuación: Los Indios han seguido con buena armonía, el cacique Julián Gordo me tiene mucho afecto, cuando tienen los toldos aquí cerca no sale de mi cuarto, el 12 próximo pasado con motivo de habérseles ido unos caballos se fueron a buscarlos y me dejó algunos de sus muebles para que se los guardase; el 7 volvieron y se hallan acampados inmediatos a este fuerte [...]. ${ }^{19} \mathrm{O}$ [...] Anoche me estuvo dando a entender el cacique que hará unos 15 o 20 años, hacia el Cabo de las Vírgenes llegaron dos embarcaciones de tres palos en tiempos de nieves que estuvieron pocos días y que luego al principio del verano volvieron las dos mismas y otra más de igual clase, que la gente que llevaban eran los más rubios, con los ojos azules, para darme a entender esto tomó un gato que tengo en mi cuarto y me dijo que los ojos eran de aquel color, por lo que considero serían ingleses y preguntándole si se hallaban allí me dijo que estuvieron pocos días que no han vuelto más por lo que noticio a um en cumplimiento de mi obligación. ${ }^{20}$

Ahora bien, nos preguntamos cuál es el lugar que se le asigna al resto de los actores sociales, tanto de un grupo como otro, en los relatos del Superintendente. En respuesta a este interrogante, en términos generales observamos que prácticamente es inexistente la mención a otros actores -salvo por casos aislados ${ }^{21}$ y sobre todo a relaciones establecidas entre los mismos. Por ejemplo, en todo el corpus existe un llamativo silencio acerca de la relación

19 AGN, Sala IX, 16.3.7 "Carta de A. Viedma a J. J. Vértiz, Floridablanca, 10 de mayo de 1781".

20 AGN, Sala IX, 16.3.7 "Carta de A. Viedma a J. J. Vértiz, Floridablanca, 13 de mayo de 1781".

21 Estos casos aislados están dados por la relación entre el piloto Goycochea y el cacique Julián cuando arriba el contingente poblador; entre dicho piloto y el joven indígena que debe transportar a Buenos Aires; el guardián del bergantín San Sebastián que le entrega su sombrero al cacique Julián; la relación entre Viedma y los parientes más cercanos del cacique, así como con caciques amigos de Julián, pero siempre en el marco de un esquema jerárquico. Un caso especial, sin embargo es el de la pobladora María de Mata quien enferma, entrega a su pequeña hija a la hermana del cacique Julián para que la amamante (Viedma [1783] 1972a). entre los distintos segmentos de la población de Floridablanca y la tehuelche. Estas omisiones se hacen aún más evidentes ante la posibilidad de la convivencia cotidiana de ambas poblaciones por determinados períodos de tiempo.

\section{Las prácticas del contacto}

La omisión sobre las relaciones también conlleva a una omisión sobre las prácticas. En el caso de las prácticas tehuelches, nos interesa destacar el notable contraste que existe entre el diario de Viedma y sus cartas, por un lado y Descripción de la costa meridional del sur llamada vulgarmente patagónica... (Viedma [1783] 1972b) por otro, donde hace un relato pormenorizado de la vida y las costumbres de los indígenas.

En el primer caso, son reiteradas las alusiones a eventos de intercambio y la reciprocidad. Éstas fueron prácticas comunes entre los tehuelches ${ }^{22}$ en cuya lógica de funcionamiento habría entrado la colonia, tal como se deja ver en los relatos del superintendente, más allá de que las mismas fueron capitalizadas y moldeadas dentro de las estrategias tradicionales de los colonizadores para entablar y afianzar las relaciones con las poblaciones locales. En su diario Viedma menciona: Los indios nos surtían de carne de guanaco, a cambio de bizcocho, tabaco y otras frioleras (Viedma [1783] 1972a: 906). $\mathrm{Al}$ margen del intercambio, la única referencia y descripción de una práctica netamente indígena se encuentra en el diario de Viedma, donde se describe con detalle el rito funerario en ocasión de la muerte de la mujer de un sobrino del cacique (Viedma [1783] 1972a: 915-916).

En la Descripción de la costa meridional del sur llamada vulgarmente patagónica... (Viedma [1783] 1972b) por el contrario, Viedma se pone en

22 El intercambio e interacción intergrupal fueron la base de la complementariedad económica y la construcción de alianzas políticas entre las diferentes comunidades indígenas de Patagonia, previo a la llegada de los europeos como durante el período colonial. Al tratarse de prácticas tradicionales y con profundidad histórica, habrían forjado en el habitus de estas comunidades una mayor predisposición y apertura para interactuar con el otro, y al mismo tiempo una mayor permeabilidad para la incorporación de personas, pautas culturales u objetos foráneos, aunque en muchos casos mediados por un proceso de resignificación, fundamentalmente en relación a los dos últimos. 
la piel de un clásico etnógrafo y realiza una narración pormenorizada de diversos aspectos de la vida y las costumbres de los tehuelches, escasamente teñida de juicios de valor, a pesar de las evidentes diferencias culturales. Precisamente, el detalle con el que se describe a los tehuelches no deja lugar a dudas sobre la participación y cuidadosa observación de las escenas por parte de Viedma, y por extensión da cuenta de una relación muy cercana entre españoles y tehuelches, propiciada por la vecindad y el contacto cotidiano, aunque nunca se haga mención de la misma en la narración etnográfica. En contraposición, en las cartas y el diario es llamativa la ausencia de referencias a la participación de la población española en actividades indígenas, sobre todo en aquellas que involucraban un alto grado de socialización, como por ejemplo: la cooperación en partidas de caza, el consumo de alimentos y de estimulantes como el tabaco y el alcohol, la participación en actividades lúdicas como las carreras ecuestres, juegos de naipes y dados, entre otras cosas. Por otro lado, tampoco se hace referencia a los indígenas participando en las prácticas españolas.

No nos interesa establecer aquí la intencionalidad del autor, pero si el efecto de sentido del discurso, donde a pesar del trato amistoso, tolerante y pacífico del contacto, se desvanece completamente la interacción entre la gran diversidad de actores sociales de ambos grupos así como la posibilidad de la intersección de sus prácticas, simplificando una realidad por demás compleja.

\section{El rol de la cultura material}

El último eje analizado en esta sección refiere al rol asignado a la cultura material en la construcción discursiva de las relaciones interétnicas en el contexto de Floridablanca. Buscamos establecer qué bienes y recursos -tanto indígenas como españoles- se movilizaron o no, la importancia de los mismos, cómo se produjo este flujo y su significado en el marco de las relaciones interétnicas. El fin último es determinar cuál es la imagen que transmite el discurso acerca de la dimensión material del contacto.

En primer lugar, una vez más se observa un claro contraste entre la precisión con que Viedma describe la cultura material propiamente tehuelche en su relato etnográfico y la ausencia total de referencias a la misma en sus cartas, el diario y los registros de contaduría. A modo de ejemplo citamos un pasaje del primero donde se describe con lujo de detalles los arreos de montar femeninos: Los arreos de la caballería en las mujeres que montan, que por lo común son yeguas, se componen de unos sillones de vaqueta o de suela si la pueden conseguir, muy bien hechos, claveteados con clavitos de latón amarillo, guarnecidos en sus extremos con abalorios de diferentes colores (cuando los tienen, formando dibujos o labores a su modo y fantasía). La cinta tiene tres argollas, la una en un extremo, y las dos en cada tercio una; la hebilla con la que abrochan o ciñen es muy grande. El freno se compone de cabezada, bocado y riendas: la cabezada es rica, guarnecida de abalorios, o de cuantas cosas tienen o pueden adquirir al propósito: las riendas y el bocado son del modo que los que usan los hombres [...] (Viedma [1783] 1972b: 947).

Por el contrario, el diario, las cartas ${ }^{23}$ y los registros de contaduría, ${ }^{24}$ no sólo son mudos respecto a la cultura material de los tehuelches sino que muestran una imagen donde lo que predomina es el flujo unidireccional de diversos elementos de la cultura material de origen criollo y europeo hacia los indígenas, pero siempre en el marco de los canales oficiales (Sanguinetti de Bórmida et al. 2005; Buscaglia y Nuviala 2007). Al respecto, son prácticamente inexistentes las menciones sobre la circulación $e$ intercambio de bienes personales de pobladores a tehuelches. La contribución de los tehuelches se vincula más a la realización de favores, mencionándose como único aporte material de los indígenas el suministro de carne de guanaco, tanto cuando la población pasó por períodos prolongados de desabastecimiento como cuando no (Viedma [1783] 1972a: 934). La circulación de la cultura material indígena entre los españoles es un elemento ausente en el discurso oficial sobre el contacto.

Sin embargo, el análisis de la evidencia arqueológica en Floridablanca ha permitido establecer que tanto la tecnología, conocimientos y/o prácticas asociadas a los tehuelches se encontraban integradas a la vida cotidiana del poblado, a diferencia de la imagen que se desprende del discurso oficial donde se registra un llamativo silencio respecto a las mismas (Buscaglia y Nuviala 2007; Bianchi Villelli 2009; Buscaglia 2009 y 2010).

23 AGN, Sala IX, 16.3.4 al 16.3.12 y 16.4.1.

24 AGN, Sala IX, 16.2.9 y 16.5 .10 y Sala XIII, 34.10.5. 


\section{CONSIDERACIONES FINALES}

A partir del análisis y la comparación de diversas fuentes documentales producidas por la administración de Floridablanca -las cartas, los registros de contaduría y el diario de Viedma-, observamos que el discurso que subyace acerca de las relaciones interétnicas en el contexto de la colonia muestra una imagen ambivalente, de convivencia estrecha, amistosa pero también circunscrita. La misma es definida a base de una serie de recurrencias y omisiones en el plano discursivo. El discurso oficial sobre el contacto transmite la imagen de un control ordenado de las relaciones interétnicas y exclusivo de ciertos actores: aquellos que detentan el poder en ambos grupos. La textualidad crea $e$ impone límites claros a través de los silencios; nada ni nadie más participa fuera de la intervención oficial, quedando al margen todo un abanico de prácticas tanto indígenas como españolas y sus intersecciones. En otras palabras, la participación indígena se encuentra relegada, al menos desde el plano discursivo, a relaciones políticas y actividades que tuvieron alguna utilidad para la colonia.

Algunas de las omisiones se hacen aún más evidentes cuando contemplamos la información sobre los tehuelches en la Descripción de la costa meridional del sur llamada vulgarmente patagónica ... (Viedma [1783] 1972b). Si bien es un discurso diferente, generado sobre la base de los modelos de relatos de viajes y etnográficos del siglo XVIII, alineados con el racionalismo iluminista (Penhos 2005), también se encuentra estrictamente asociado al poder colonial. En este sentido, el grado de conocimiento sobre los tehuelches que el autor -posicionado como un observador externo- busca transmitir en dicha obra, demuestra el poder de penetración de la mirada colonial en la cultura del otro, y la aprehensión de un saber que en el contexto mayor del colonialismo servirá a los fines de controlarlo y dominarlo.

La imagen que surge del discurso acerca del contacto en Floridablanca, claramente relega a los indígenas a un rol pasivo y externo a la dinámica social de la colonia, a pesar de la conocida hospitalidad y afabilidad de los tehuelches, del trato cotidiano propiciado por la vecindad en las instalaciones y de la necesidad que el poblado tenía de la ayuda indígena. La conjunción de estos elementos nos lleva a pensar que el discurso oficial está ofreciendo una imagen recortada de las relaciones interétnicas. Imagen que buscaría transmitir, especialmente ante la audiencia de las autoridades virreinales, la idea de distanciamiento social y material entre ambos grupos $y$, sobre todo el control que los españoles tenían sobre la situación del encuentro a fin de mantener un modelo sociedad ajustado a los ideales del proyecto.

La relación pacífica con los tehuelches, sumada a un contexto atravesado por continuas dificultades, característico de las empresas de colonización iniciales, pudo haber abierto el juego a nuevas posibilidades para los pobladores de la colonia frente a aquellas pautas que se buscó imponer desde el proyecto colonizador. Sin embargo, algunas de las prácticas y las costumbres de carácter más cotidiano de los tehuelches descansaban sobre principios que estaban en contradicción con aquellos asociados a la disciplina moral, laboral y familiar fomentados desde el plan de colonización. La interacción con los indígenas posiblemente puso aún más en evidencia la arbitrariedad de aquellos principios vinculados a un ideal particular de sociedad, generando de este modo un espacio donde la redefinición del mismo era posible, sobre todo en el caso de un contexto de colonización inicial como el que representa Floridablanca.

Para finalizar, pensamos que el Superintendente Antonio de Viedma participó de un doble juego en el que por un lado habría impuesto pocas restricciones en la práctica a la relación entre ambas poblaciones, lo que se deja entrever tanto a través de una imagen de convivencia pacífica y cotidiana en las narrativas como aquella que surge desde la materialidad. Pero por otro lado, dado que de su persona dependía la instrumentación y el éxito del plan de colonización, fue sumamente cuidadoso a la hora de decidir qué información transmitir o no sobre la colonia en sus comunicaciones a las autoridades virreinales, sobre todo teniendo en cuenta sus dos fracasos previos en el Fuerte San José y en el campamento de Puerto Deseado. Como ya señalamos, desde un principio la estrategia del gobierno de la colonia fue la de canalizar las energías, tiempos y recursos a la materialización de las directrices del plan y crear a través del discurso, una imagen de coherencia, orden y control en el contexto de la colonia en función de los ideales del modelo de orden social, que en definitiva redundará en beneficio de su propia legitimación. 
Como señalara Zygmunt Bauman (2007: 161), todo modelo de orden es selectivo y exige el recorte, la poda, la segregación, la separación o extirpación de aquellas partes de la materia prima humana que demuestren ser ineptas para ese orden, es decir que sean incapaces o no se les permita encajar en ninguno de sus nichos. En nuestro caso de estudio, las prácticas y el habitus de los tehuelches no habrían encajado con el ideal de sociedad proyectado para Floridablanca. Sin embargo, el recorte habría estado más asociado al plano discursivo, que al plano de las prácticas cotidianas de ambas poblaciones, mostrando con ello la complejidad que encierran las relaciones interétnicas en el marco del colonialismo.

\section{FUENTES DE CONSULTA}

a) Inéditas

ARCHIVO GENERAL DE LA NACIÓN, División Colonia, Sección Gobierno, Sala IX, legajos 16.3 .2 al 16.3.12, 16.4.4, 16.4.5 y Sala XIII, legajo 34.10.5.

ARCHIVO GENERAL DE INDIAS, Patronato Real, Legajo 33, Sección Gobierno, Buenos Aires, legajo 326.

b) Impresas

ANSON, GEORGE [1749] 1853. A Voyage around the World in the years of 1740,1741, 1742, 1743, 1744. London.

BARNE, JORGE 1969. Viaje que hizo el San Martín desde Buenos Aires al puerto de San Julián, el año de 1752 y del de un indio paraguayo, que desde dicho puerto vino por tierra hasta Buenos Aires. Viajes y Expediciones a los Campos de Buenos Aires y a las Costas de la Patagonia. En: Colección Pedro De Angelis, Plus Ultra, Buenos Aires, Tomo IV. Pp. 66-94.

BOURNE, BENJAMIN. F. [1853] 1998. Cautivo en la Patagonia. Emecé Editores S. A., Buenos Aires.

COAN, TITUS [1880] 2006. Aventuras en Patagonia. Un Viaje de Exploración de Dos Misioneros Norteamericanos. Noviembre 1833 -Marzo 1834. Zagier \& Urruty Publications, Buenos Aires.

D'ORBIGNY, ALCIDE [1835-1847] 1999. Viaje por la América Meridional. Tomo II. Ed. Emecé, Buenos Aires.

FITZ ROY, ROBERT 1839. Proceedings of the Second expedition, 1831-1836, under the command of Captain..., $R$. N., an narrative of the surveying voyages of his majesty's ships Adventures and Beagle, between the years 1826-1836, describing their examination of the southern shores of South America, and the Beagle's circumnavigation of the globe. Impreso por Henry Colburn, London.

FLETCHER, FRANCIS 1854. The World encompassed by Sir Francis Drake. Hakluyt Society, London.

LOZANO, PEDRO P. [1745] 1972. Diario de un viaje a la costa del la Mar Magallánica en 1745 desde Buenos Aires hasta el Estrecho de Magallanes formado sobre las observaciones de los Padres Cardiel y Quiroga por el Padre Pedro Lozano. En: Colección Pedro De Angelis, Tomo III. Plus Ultra. Buenos Aires. Pp. 587-633.

MALASPINA, ALEJANDRO [1789-1795] 1938. Viaje al Río de la Plata en el siglo XVIII. Sociedad Argentina de Historia, Buenos Aires

MORRIS, ISAAC [1740-1746] s/f. Narrative of the Dangers and Distresses which Befel Isaac Morris and Seven More of the Crew, Belonging to The Wager Store-Ship which Attended Comodore Anson in his Voyage to the South Sea. Impreso por St. Birt, London.

MUSTERS, GEORGE C. [1871] 1997. Vida entre los Patagones. Un año de excursiones por tierras no frecuentadas desde el Estrecho de Magallanes hasta el Río Negro. Ed. Elefante Blanco, Buenos Aires.

NARBOURUGH, JOHN, JASMEN TASMAN, JOHN WOOD y FREDERICK MARTEN 1694. An Account of Several Late Voyages and Discoveries to the South and North. Printed for Sam, Smith and Benjamin Walford, London.

PIGAFETTA, ANTONIO 2001. Primer Viaje Alrededor del Mundo. Ed. Elefante Blanco, Buenos Aires.

ROMERO, TOMÁS A. [1788] 1939. Propuesta de .... Francisco de Paula Sanz. Buenos Aires 29 de julio de 1788. En: Revista de la Biblioteca Nacional II(8):660-671. Imprenta de la Biblioteca Nacional, Buenos Aires.

VIEDMA, ANTONIO [1783] 1972a. Diario de Viedma. En Colección Pedro De Angelis, Tomo VIII, volumen B. Ed. Plus Ultra, Buenos Aires. Pp. 845-936.

[1783] 1972b. Descripción de la costa meridional del sur llamada vulgarmente patagónica. Relación de sus terrenos, producciones, brutos, aves y peces; indios que la habitan, su religión, costumbres, vestido y trato desde el Puerto de Santa Elena en 44 grados hasta el de la Virgen en 52 y boca del estrecho de Magallanes. Refiérese cuanto en dicha costa y tierra caminó y reconoció por sí. D. Antonio de Viedma, en el tiempo de su destino en aquellos establecimientos, y su particular comisión en el de San Julián, con las demás noticias que pudo adquirir de los indios. En Colección Pedro De Angelis, Tomo VIII, volumen B. Ed. Plus Ultra. Buenos Aires. Pp. 937-966. 
VILLARINO, BASILIO. 1972. Diario del Piloto de la Real Armada Don Basilio Villarino del reconocimiento que hizo del Río Negro en la costa oriental de Patagonia el año de 1782. En Colección Pedro De Angelis, Tomo VIII, volumen B. Ed. Plus Ultra, Buenos Aires. Pp. 967-1150.

\section{BIBLIOGRAFÍA}

BAUMAN, ZYGMUNT. 2007. Amor Líquido. Acerca de la fragilidad de los vínculos humanos. Ed. Fondo de Cultura Económica, Buenos Aires.

BHABHA, HOMI. 2002. El Lugar de la cultura. Ed. Manantial, Buenos Aires.

BIANCHI VILLELLI, MARCIA. 2007. ¿Espacios de cambio social? Los espacios no proyectados por la Corona en la población española de Floridablanca (San Julián, Siglo XVIII). Arqueología de Fuego-Patagonia. Levantando piedras, desenterrando huesos...y develando arcanos. Editado por F. Morello, A. Prieto, M. Martinic y C. Bahamonde. Ediciones CEQUA, Punta Arenas. Pp. 787-799. 2009. Cambio social y prácticas en el orden colonial. Arqueología Histórica en Floridablanca (San Julián, Argentina, siglo XVIII). Tesis Doctoral. British Archaeological Reports International Series. Ed. A. Izeta. South American Archeological Series $N^{\circ}$ S2039. Inglaterra.

BIANCHI VILLELLI, MARCIA, MARÍA XIMENA SENATORE y SILVANA BUSCAGLIA. 2005 Identificación de nuevas estructuras en la colonia de Floridablanca. Aproximaciones históricas, arqueológicas y geofísicas. En Actas del VI Congreso Argentino de Americanistas. Sociedad Argentina de Americanistas. Universidad del Salvador, Ed. Dunken. Buenos Aires. Pp. 411-434.

BOSONI, CLAUDIA. 2010. Entre lo dicho y lo hecho: Prácticas productivas en la colonia española de Floridablanca (Patagonia, siglo XVIII). Tesis de Licenciatura, FFyLUBA. MS.

BOURDIEU, PIERRE. 1999. Outline of a theory of practice. Cambridge University Press, Cambridge.

BUSCAGLIA, SILVANA. 2008. Los marinos malditos. Identidad, poder y materialidad (San Julián, Pcia. de Santa Cruz, Siglo XVIII). En Vestigios. Revista latinoamericana de Arqueología Histórica 2 (1): 35-62.

2009. Relaciones de Poder y Dinámica Interétnica en Floridablanca. Una Perspectiva Histórica y Arqueológica (San Julián, Siglo XVIII). Tesis Doctoral, FFy L-UBA. MS.

2010. Fronteras permeables en Floridablanca: Agencia indígena y vida cotidiana (Patagonia, Siglo XVIII). En Temas y problemas de la Arqueología Histórica. Editado por M. Ramos; A. Tapia; F. Bognanni; M. Fernández; V. Helfer; C. Landa; M. Lanza; E. Montanari; E. Néspolo y V. Pineau. Programa de Arqueología Histórica y Estudios Pluridisciplinarios (PROARHEP). Departamento de Ciencias Sociales. Universidad Nacional de Luján, Buenos Aires.

BUSCAGLIA, SILVANA, MARÍA XIMENA SENATORE, MARCIA BIANCHI VILLELLI, PAULA PALOMBO y CINTIA MILANES. 2005. El Fuerte de la Colonia de Floridablanca: primera integración de la evidencia histórica, arqueológica y geofísica. En Actas del V Congreso de Americanistas, Sociedad Argentina de Americanistas. Universidad del Salvador. Ed. Dunken, Buenos Aires. Pp. 469-484.

BUSCAGLIA, SILVANA y VICTORIA NUVIALA. 2007. Pocos espejitos de colores. La construcción material del contacto en Floridablanca (San Julián, siglo XVIII). En Arqueología de Fuego-Patagonia. Levantando Piedras, Desenterrando Huesos... y Develando Arcanos. Editado por F. Morello, A. Prieto, M. Martinic y C. Bahamonde. Ediciones CEQUA, Punta Arenas, Chile. Pp. 813-824.

CARRERA STAMPA, MAMUEL. 1949. The evolution of weights and measures in the New Spain. The Hispanic American Historical Review 29: 1-24.

CASTRO-GÓMEZ, SANTIAGO Y EDUARDO. MENDIETA (eds). 1998. Teorías Sin Disciplina (Latinoamericanismo, Poscolonialidad y Globalización en Debate). México, Ed. Purrúa. Edición digital elaborada por J. L. GómezMartínez para Proyecto Ensayo Hispánico, http://www. ensayistas.org/critica/teoria/castro/.

CHIARAMONTE, JOSÉ C. 1962. Ensayos sobre la "Ilustración Argentina”. Universidad Nacional del Litoral, Paraná. 1977. Pensamiento de la Ilustración. Economía y sociedad Iberoamericana en el siglo XVIII. Biblioteca Ayacucho, Caracas.

DESTÉFANI, LAURIO H. 1984. Cap. V: La colonización patagónica. En Historia Marítima Argentina, Tomo IV, IPN Editores, Buenos Aires. Pp. 179-217.

DE PAULA, ALBERTO S. J. 1984. Fortificaciones en el litoral marítimo patagónico durante el dominio español. En II Congreso de Historia Argentina y Regional, Tomo II. Academia Nacional de la Historia, Buenos Aires. Pp. 227-247.

DI PAOLO, LOREN. D. 2001. Social skins. Orthodoxies and practices of dressing in the early colonial Mississippi Valley. Journal of Social Archaeology 1 (2): 172-189.

DUMRAUF, CLEMENTE. I. 1992. Cap. IV: La ocupación de Patagonia. En Historia de Chubut. Ed. Plus Ultra, Buenos Aires. Pp. 77-112. 
ENTRAigAS, RAÚl. 1960. El Fuerte de Río Negro. Don Bosco, Buenos Aires.

FANON, FRANZ. 1986. Black skin, whites masks. Pluto, London.

FOUCAULT, MICHEL. 1984. La Arqueología del saber. Siglo XXI editores, México, DF. 1992 [1970]. El Orden del Discurso. Tusquets Editores, Barcelona.

GIDDENS, ANTHONY. 1976. New Rules of the Sociological Method. Basic Books, New York.

1995. La constitución de la sociedad. Bases para la teoría de la estructuración. Amorrortu Editores, Buenos Aires.

GORLA, CARLOS MARÍA. 1984. Los establecimientos españoles en la Patagonia: Estudio institucional. Publicaciones de la Escuela de Estudios Hispano-Americanos de Sevilla, Sevilla.

GOSDEN, CHRIS. 1999. Cap. 8: Colonialism, ethnicity and post-colonialism. En Anthropology and Archaeology. A changing relationship. Routledge, London and New York .Pp. 179-205.

2001. Postcolonial archaeology. Issues of culture, identity and knowledge. En I. Hodder (ed.) Archaeological Theory Today. Polity Press, Cambridge. Pp. 241-262.

GUHA, RANAJIT. 1988. On some aspects of the historiography of Colonial India. En Selected Subaltern Studies Ranajit Guha y Gayatri Spivak Chakravorty (eds.). Oxford University Press, Oxford.

JONES, SIÂN. 1997. The Archaeology of Ethnicity. Routledge, London.

1999. Historical categories and the praxis of identity: the interpretation of ethnicity in historical archaeology. En Historical Archaeology from the Edge. Routledge, London

LIEBMANN, MATTHEW. J. y UZMA. Z. RIVZI (eds). 2008. Archaeology and the Postcolonial Critique., Altamira Press, Lanham, New York, Toronto, Plymouth and UK.

LIGHTFOOT, KEEN. G., ANTOINETTE MARTINEZ y ANN M. SCHIFF. 1998. Daily practice and material culture in pluralistic social settings: an archaeological study of culture change and persistence from Fort Ross, California. American Antiquity 63 (2): 199-222.

LISTA, RAMÓN.1998. Los indios tehuelches. Una raza que desaparece. En Ramón Lista. Obras. Editorial Confluencia, Buenos Aires.

LUIZ, MARÍA T. 2006. Relaciones fronterizas en Patagonia. La convivencia hispano-indígena a fines del período colonial. Asociación Hanis, Universidad Nacional de la Patagonia San Juan Bosco, Ushuaia.
LYNCH, JOHN. 1992. The institutional framework of colonial Spanish America. Journal of Latin American Studies 24: 69-81.

MALLON, FLORENCIA. 1994. The promise and dilemma of subaltern studies: perspectives from Latin American History. The American Historical Review 99 (5): 1491-1515.

MARSCHOFF, MARÍA. [2004] 2007. Gato por libre. Prácticas alimenticias en Floridablanca. Serie Proyecto Floridablanca. Editorial Teseo, Buenos Aires.

2010. Experimentación Social e Identidad. Arqueología e Historia en Floridablanca (Siglo XVIII). Tesis doctoral, FFy L-UBA. MS.

MARTINIC, MATEO. 1995. Los Aónikenk. Historia y cultura. Ediciones de la Universidad de Magallanes, Punta Arenas. 2008. El comercio sexual entre las mujeres Aónikenk y los foráneos. Magallania 36(1):31-36.

MESKELL, LYNN. 2001. Archaeologies of identity. En Archaeological Theory Today, editado por I. Hodder. Polity Press, Cambridge. Pp. 187-213.

MOLINA MARTÍNEZ, MIGUEL. 1987. El giennense Antonio Viedma, colonizador y cronista de la costa patagónica. Boletín del Instituto de Estudios Giennenses 132: 39-62.

NACUZZI, LIDIA. R. 2002. Francisco de Viedma, un "Cacique Blanco" en tierra de indios. En Funcionarios, Diplomáticos, guerreros. Miradas hacia el otro en las fronteras de Pampa y Patagonia (siglos XVIII y XIX). Lidia R. Nacuzzi (comp.). Sociedad Argentina de Antropología, Buenos Aires, Pp. 25-64.

2005. Identidades Impuestas. Tehuelches, Aucas y Pampas en el Norte de la Patagonia. Sociedad Argentina de Antropología, Buenos Aires ( $2^{\circ}$ edición).

NUVIALA, VICTORIA. 2008. Materializando Identidades: los artefactos de uso personal en la comunicación no verbal de las identidades (Patagonia -Siglo XVIII). Tesis de Licenciatura, FFyL-UBA. MS

PENHOS, MARTA. 2005. Ver, conocer, dominar. Imágenes de Sudamérica a fines del siglo XVIII. Ed. Siglo XXI, Buenos Aires.

PRAKASH, GYAN. 1994. Subaltern studies as postcolonial criticism. The American Historical Review 99(5):1475-1490.

PUNTA, ANA I. 1998. Córdoba borbónica: persistencias coloniales en tiempo de reformas (1750-1800). Universidad Nacional de Córdoba, Córdoba.

RAMOS PÉREZ, DEMETRIO. 1992. La exploración de San Julián en la costa de Patagonia y el Marqués de Valdelirios, Revista de Indias 49: 497-511.

RATTO, SILVIA. 2007. Indios y cristianos. Entre la guerra y la paz en las fronteras. Ed. Sudamericana, Buenos Aires. 
RODRÍGUEZ, ILEANA. 1998. Hegemonía y dominio: subalternidad, un significado flotante. En S. Castro-Gómez y E. Mendieta (eds.) Teorías Sin Disciplina (Latinoamericanismo, Poscolonialidad y Globalización en Debate). México, Ed. Purrúa. Edición digital elaborada por José Luis Gómez-Martínez para Proyecto Ensayo Hispánico, http://www.ensayistas.org/critica/teoria/castro/.

2001. Convergencia de tiempos. Estudios subalternos/ contextos latinoamericanos. Estado, cultura, subalternidad. Rodopi, Ámsterdam.

RODRÍGUEZ DÍAZ, LAURA. 1975. Reforma e Ilustración en la España del siglo XVIII. Pedro Rodríguez de Campomanes. Fundación Universitaria Española, Madrid.

ROTHSCHILD, NANN. A. 2003. Colonial encounters in a Native American landscape. The Spanish and Dutch in North America. Smithsonian Books. Washington and London.

SAHLINS, MARSHALL. 1981. Historical metaphors and mythical realities: Structure in the early history of the Sándwich Islands Kingdom. Special Publication № 1 , Association for the Study of Anthropology in Oceania. University of Michigan Press, Ann Arbor.

1985. Islands of History. University of Chicago Press, Chicago.

1995. How "Natives" Think: about Captain Cook, for example. The University Chicago Press, Chicago.

SAID, EDWARD W. 2006. Orientalismo. Ed. De Bolsillo, Barcelona.

SANGUINETTI DE BÓRMIDA, AMALIA. C., MARÍA XIMENA SENATORE y SILVANA BUSCAGLIA. 2005. Patagonia en los confines de la sociedad moderna. Fronteras materiales en Floridablanca (siglo XVIII). En La Frontera: Realidades y Representaciones. Ed. Dunken, Buenos Aires. Pp. 69-84.

SARRAILH, JEAN. 1992. La España Ilustrada de la segunda mitad del Siglo XVIII. Fondo de Cultura Económica, Madrid.

2002. Discursos iluministas e ordem social: representações materiais na colônia de Floridablanca em San Julián. (Patagônia, século XVIII). En: Arqueologia da Sociedade Moderna na América do Sul. Cultura Material, Discursos e Prácticas, editado por Zarankin A. y M. X. Ediciones del Tridente, Buenos Aires. Pp. 87-106.

[2003] 2007. Arqueología e historia en la colonia española de Floridablanca. Patagonia, siglo XVIII.
Serie Arqueología Histórica. Proyecto Floridablanca. Editorial Teseo, Buenos Aires.

2004. Orden social y orden material en la colonia española de Floridablanca (Patagonia, siglo XVIII). En: Contra Viento y Marea. Arqueología de la Patagonia. INAPL y SAA, Buenos Aires. Pp. 659-669.

2005. Enlightened discourse, representations and social practices in the Spanish settlement of Floridablanca (Patagonia, 18th century). En: Global Archaeological Theory, Contextual Voices and Contemporary Thoughts, P. P Funari, A. Zarankin \& E. Stobel (eds). Springer, New York. Pp. 559-669.

SENATORE, MARÍA XIMENA, SILVANA BUSCAGLIA, MARCIA BIANCHI VILLELLI, MARÍA MARSCHOFF, PAULA PALOMBO, VICTORIA NUVIALA, CINTIA MILANÉS y CLAUDIA BOSONI 2007. Imágenes de Floridablanca. La construcción material y narrativa de la Colonia Española de San Julián (Siglo XVIII). En: Arqueología de Fuego-Patagonia. Levantando Piedras, Desenterrando Huesos... y Develando Arcanos. Morello F., A. Prieto, M. Martinic y C. Bahamonde (eds.). Ediciones CEQUA, Punta Arenas. Pp. 801-812.

SENATORE, MARÍA XIMENA, MARÍA MARSCHOFF, MARCIA BIANCHI VILLELLI, SILVANA BUSCAGLIA, V.ICTORIA NUVIALA, CLAUDIA BOSONI y LAURA STARÓPOLI 2008. Una arqueología de las prácticas cotidianas en Floridablanca (Patagonia, siglo XVIII). En: Arqueología en el extremo sur del continente Americano (Borrero L. A y N. V. Franco comp.), Ed. Dunken, Buenos Aires. Pp. 81-117.

SPIVAK, GAYATRI C. 1994. Can the subaltern speak? En: Colonial and Poscolonial Theory. P. Williams y L. Chrisman (eds.). Columbia University Press, New York.

STEIN, GIL. J. 2005. Introduction: The comparative archaeology of colonial encounters. En G. J. Stein (ed.) The Archaeology of Colonial Encounters: Comparative Perspectives: 1-29. School of American Research Press, Santa Fe.

VIVES, FERRADIZ SÁNCHEZ, JAIME 2006, Cap. I: Tras los pasos de una arqueología postcolonial. En Negociando encuentros: situaciones coloniales e intercambios en la costa oriental de la Península Ibérica (Siglos VIII-VI AC): 27-48. Ed. Bellaterra, Barcelona.

VOSS, BARBARA L. 2008. The Archaeology of Ethnogenesis. Race and sexuality in Colonial San Francisco. Berkeley and Los Angeles, University California Press. 
SILVANA BUSCAGLIA 